\title{
IR Spectra, Elastic and Dielectric Properties of Li-Mn Ferrite
}

\author{
S. A. Mazen and N. I. Abu-Elsaad \\ Magnetic Semiconductor Laboratory, Physics Department, Faculty of Science, Zagazig University, Zagazig, Egypt \\ Correspondence should be addressed to S. A. Mazen, dr.saidmazen@gmail.com
}

Received 13 August 2012; Accepted 6 September 2012

Academic Editors: A. N. Kocharian and H.-D. Yang

Copyright (c) 2012 S. A. Mazen and N. I. Abu-Elsaad. This is an open access article distributed under the Creative Commons Attribution License, which permits unrestricted use, distribution, and reproduction in any medium, provided the original work is properly cited.

\begin{abstract}
Polycrystalline ferrites, $\mathrm{Li}_{0.5-0.5 x} \mathrm{Mn}_{x} \mathrm{Fe}_{2.5-0.5 x} \mathrm{O}_{4}$, (where $x=0.0,0.1,0.3,0.5,0.7,0.9$, and 1.0), were prepared by using ceramic method. Single phase cubic structure was confirmed by X-ray diffractometer. The lattice parameter "a" was found to increase with increasing $\mathrm{Mn}^{2+}$ ion substitution. IR spectra of the samples were recorded from 200 to $1000 \mathrm{~cm}^{-1}$. The two primary bands corresponding to tetrahedral $v_{\mathrm{A}}$ and octahedral $v_{\mathrm{B}}$ were observed at about $575 \mathrm{~cm}^{-1}$ and $370 \mathrm{~cm}^{-1}$, respectively. Elastic properties of these mixed ferrites were estimated as a function of composition. Young's modulus $(E)$, rigidity modulus $(G)$, bulk modulus $(B)$, Debye temperature $\left(\theta_{D}\right)$, and mean sound velocity $\left(V_{m}\right)$ were calculated from the transverse $\left(V_{t}\right)$ and longitudinal $\left(V_{1}\right)$ wave velocities. The variation of elastic moduli with composition was interpreted in terms of binding forces between the atoms of spinel lattice. AC conductivity $\tilde{\sigma}$ and dielectric properties of the samples were measured at room temperature over $100 \mathrm{~Hz}-1 \mathrm{MHz}$. The electrical conduction mechanism could be explained with the electron hopping model. Frequency exponential factor $(s)$ was calculated and it was found between 0.4 and 0.8 .
\end{abstract}

\section{Introduction}

Polycrystalline ferrites have very important structural, magnetic, electrical, and dielectric properties that are dependent on various factors, such as method of preparation, substitution of cations, and microstructure $[1,2]$. Introduction of a relatively small amount of foreign ions can change the properties of ferrites [3]. It can provide us with information for obtaining a high-quality ferrite for particular applications. Modification in electric and magnetic properties of lithium ferrites by substitution of different ions has been extensively studied [4-6].

Infrared spectroscopy was used to determine the local symmetry of crystalline and noncrystalline solids and to study the ordering phenomenon in ferrites [6]. IR absorption bands mainly appear due to the vibrations of oxygen ions with cations at various frequencies. The frequencies depend upon cation masses, lattice parameter, and cation-oxygen bonding, and so forth. [7].

Ultrasonic pulse transmission (UPT) is a very common technique for studying elastic constants. However, a new technique based on infrared spectroscopy has been developed by Modi et al. [8] for studying the elastic properties of spinel and garnet ferrites. The elastic constants are of much importance because they reveal the nature of binding forces in solids and help to understand thermal properties of the solids [9]. Elastic properties of spinel ferrites have not been studied so systematically as their magnetic and electrical properties. Moreover, there is a need for a thorough study of the elastic behaviour of these ferrites with new compositions possessing certain desired elastic properties.

The present work was aimed to estimate elastic properties of Li-Mn ferrite using IR technique. Also, dielectric properties of this ferrite were investigated at room temperature.

\section{Experimental Techniques}

Polycrystalline Li-Mn ferrites, $\mathrm{Li}_{0.5-0.5 x} \mathrm{Mn}_{x} \mathrm{Fe}_{2.5-0.5 x} \mathrm{O}_{4} ; 0.0 \leq$ $x \leq 1.0$, were prepared by the standard ceramic method. Experimental details were reported previously $[4,10,11]$. A single phase spinel structure was recorded for all compositions using X-ray diffractometer, XRD, employing $\mathrm{Cu}$ $K_{\alpha}$ radiation $(\lambda=1.5405 \AA)$ (type PHILIPS X'Pert Diffractometer). IR spectra over $200-1000 \mathrm{~cm}^{-1}$ were recorded at room temperature by using an infrared spectrometer, 
(model 1430, PerkinElmer). Dielectric measurements were conducted at room temperature over $100 \mathrm{~Hz}-1 \mathrm{MHz}$ by using a RLC (Model PM6306 FLUKA). Disk samples of $13 \mathrm{~mm}$ in diameter and $3-5 \mathrm{~mm}$ in thickness were used for dielectric measurement with silver electrode.

The AC conductivity measurements were carried out using the complex impedance technique and calculated from this equation:

$$
\tilde{\sigma}^{*}=Z^{-1} \frac{t}{A}
$$

The dielectric constant $\left(\varepsilon^{\prime}\right)$ and dielectric loss $\left(\varepsilon^{\prime \prime}\right)$ were calculated from AC conductivity $(\tilde{\sigma})$ and the dielectric loss tangent $(\tan \delta)$ using the following formulae [12]:

$$
\begin{aligned}
\mathcal{\varepsilon}^{\prime \prime}=\varepsilon_{o} \frac{\tilde{\sigma}}{f} & =1.8 \times 10^{10} \frac{\tilde{\sigma}}{f}, \\
\varepsilon^{\prime} & =\frac{\varepsilon^{\prime \prime}}{\tan \delta},
\end{aligned}
$$

where $f$ is the frequency of the applied field.

\section{Results and Discussion}

3.1. X-Ray Analysis and IR Absorption. Figure 1 shows the $\mathrm{X}$-ray diffraction patterns for the above-mentioned composition of Li-Mn ferrite. The main reflection planes of the spinel structure of ferrites are shown in the X-ray patterns where these planes are (111), (210), (211), (220), (311), (222), (400), (422), (333), (440), and (533). The samples of $x=0.7,0.9$ and 1 contain a little of second phase of $\alpha-\mathrm{Fe}_{2} \mathrm{O}_{3}$. In general, the behaviour of diffraction pattern proved that the prepared samples were formed in the cubic spinel structure according to JCPDS card. The estimated values of the experimental lattice parameter " $a_{\exp }$ " as a function of composition are presented in Figure 2. It is found that the lattice parameter increases with the increase of $\mathrm{Mn}$ content. This increment of the lattice parameter could be explained on the basis of ionic radii, where the radius of $\mathrm{Mn}^{2+}$ ion $(0.08 \mathrm{~nm})$ is larger than that of $\mathrm{Li}^{+}(0.073 \mathrm{~nm})$ and $\mathrm{Fe}^{3+}(0.064 \mathrm{~nm})$ ions. The $\mathrm{Mn}^{2+}$ ions successively replace the $\mathrm{Li}^{+}$and $\mathrm{Fe}^{3+}$ ions. The unit cell expands to accumulate the larger ion, so it is expected to increase the lattice parameter. The uniform increase in lattice constant with manganese substitution indicates that lattice expands without disturbing the symmetry of lattice [13]. A similar variation has also been reported by Ravinder et al. [9].

The IR spectra of the investigated composition for LiMn ferrite are shown in Figure 3. The absorption bands are summarized in Table 1. No absorption bands were observed above $1000 \mathrm{~cm}^{-1}$. The IR spectrum of pure Li ferrite $(x=$ 0.0) has been analyzed in detail by Mazen et al. [14]. It is noticed that the primary band $v_{1}^{*}$ and the second absorption band $v_{2}^{*}$ are in the ranges of $585-546 \mathrm{~cm}^{-1}$ and $379-372 \mathrm{~cm}^{-1}$, respectively. The values of $\nu_{1}^{*}$ are higher than those of $v_{2}^{*}$, indicating that the normal mode of vibration of the tetrahedral complexes is higher than that of the corresponding octahedral site. This may be due to the shorter

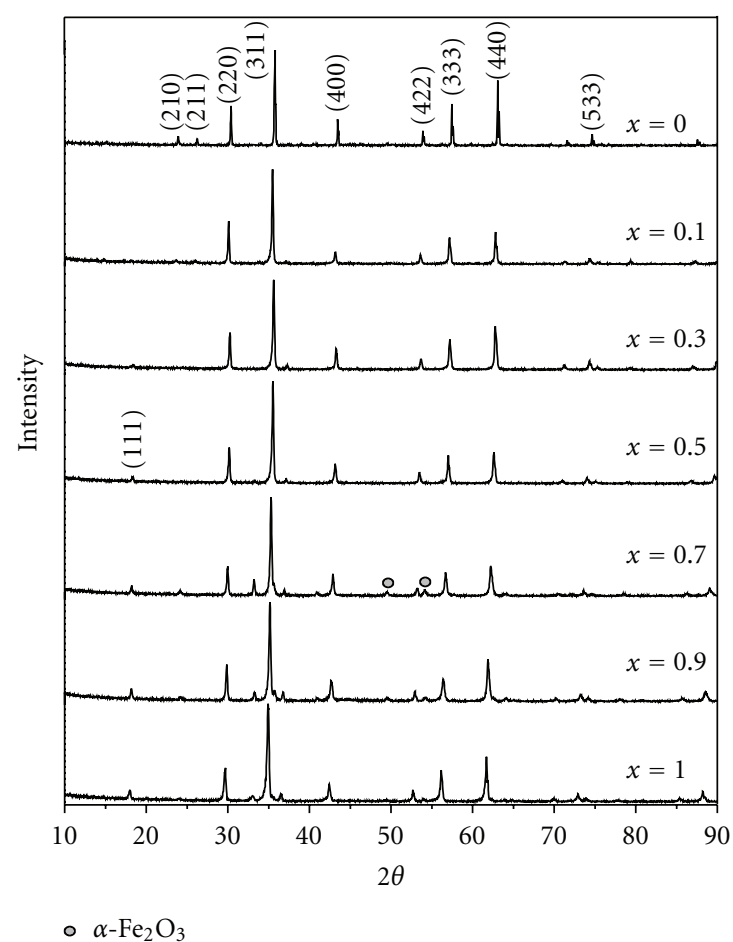

FIGURE 1: X-Ray diffraction pattern of $\mathrm{Li}_{0.5-0.5 \mathrm{x}} \mathrm{Mn}_{x} \mathrm{Fe}_{2.5-0.5 x} \mathrm{O}_{4}(x=$ $0.0,0.1,0.3,0.5,0.7,0.9$, and 1.0 ).

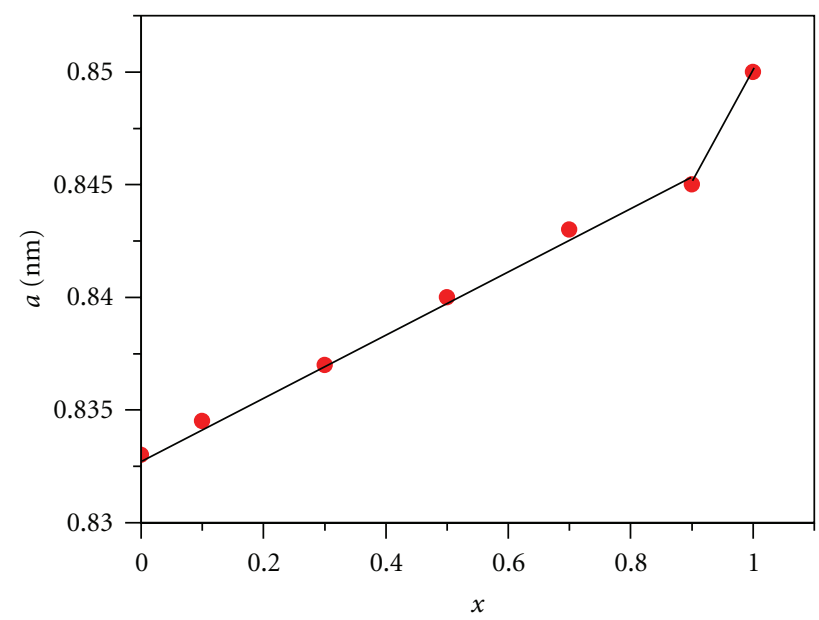

Figure 2: Variation of experimental lattice parameter with Mn substitution.

bond length of the tetrahedral site $\left(R_{A}=1.89 \AA\right)$ than that of the octahedral site $\left(R_{B}=1.99 \AA\right)$ [15]. From Table 1 it is obvious that by introducing $\mathrm{Mn}^{2+}$, the band $v_{1}^{*}$ shifts slightly towards lower frequency meanwhile the band $v_{2}^{*}$ has no shift or change with frequency. The third band $v_{3}$ appears at $325 \mathrm{~cm}^{-1}$ for $x=0.0$ and changes to weak shoulder for $x \geq 0.1$. This band could be attributed to the divalent metal ion-oxygen complexes at octahedral sites. Hence, it indicates the presence of a small amount of $\mathrm{Fe}^{2+}$ ions [16]. The fourth vibrational band $v_{4}\left(265 \mathrm{~cm}^{-1}\right)$ is due to the lattice vibration [17]. 
TABLE 1: IR absorption bands of the ferrites.

\begin{tabular}{|c|c|c|c|c|c|c|c|c|}
\hline \multirow{2}{*}{$x$} & \multicolumn{4}{|c|}{ Tetrahedral site (A-site) } & \multicolumn{4}{|c|}{ Octahedral site (B-site) } \\
\hline & $v_{1}(1)$ & $v_{1}(2)$ & $v_{1}^{*}$ & $v_{1}(3)$ & $v_{2}(1)$ & $v_{2}^{*}$ & $v_{3}$ & $v_{4}$ \\
\hline 0.0 & 707 & 667 & 585 & 543 & 457 & 379 & 325 & 267 \\
\hline 0.1 & $704(w, s h)$ & - & 578 & $530(w, s h)$ & 450 & 375 & $330 w$ & 265 \\
\hline 0.3 & - & - & 584 & - & - & 372 & $327 w$ & 267 \\
\hline 0.5 & - & - & 557 & - & - & 374 & $310 w$ & 268 \\
\hline 0.7 & - & - & 553 & - & - & 375 & $324 w$ & 265 \\
\hline 0.9 & - & - & 547 & - & - & 376 & $327 w$ & 265 \\
\hline 1 & - & - & 546 & - & - & 376 & $325 w$ & - \\
\hline
\end{tabular}

${ }^{*}$ The primary band, w: weak, and sh: shoulder.

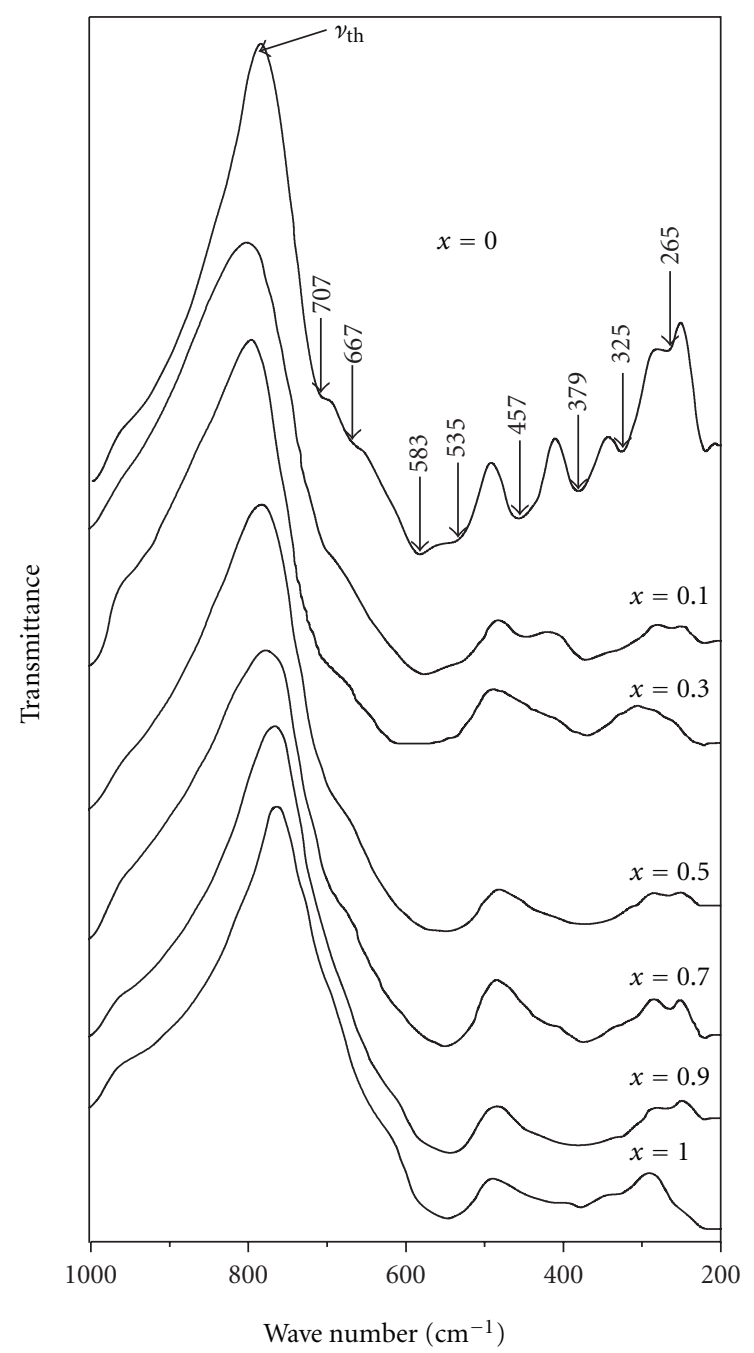

FIgURE 3: IR absorption spectra of the mixed Li-Mn ferrites.

The spectrum indicates a splitting in the absorption bands; that is, the first primary band $\left(v_{1}^{*}\right)$ consists of two shoulders $v_{1}(1)$ at 710 and $v_{1}(2)$ at $670 \mathrm{~cm}^{-1}$ and a small band $v_{1}(3)$ at $535 \mathrm{~cm}^{-1}$. It has been shown that the presence of $\mathrm{Fe}^{2+}$ ions in ferrites can cause splitting of or produce shoulders on the absorption bands [18]. This is attributed to the Jahn-Teller distortion caused by $\mathrm{Fe}^{2+}$, which cause

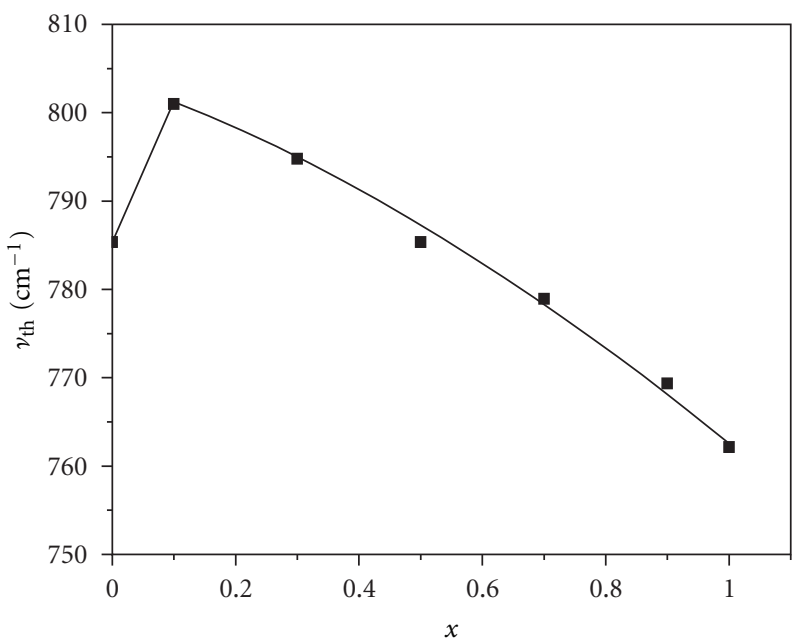

FIGURE 4: Dependence of threshold frequency $v_{\text {th }}$ with composition $x$.

local deformations in the crystal field potential and hence lead to the splitting of the band $v_{1}^{*}$. These bands appeared in the samples with low content of $\mathrm{Mn}(x=0.0$ and 0.1$)$ and completely disappeared at high concentration of Mn.

According to Tarte [19] and Mazen et al. [14], the high frequency band $v_{2}(1)$ recorded only for $x=0.0$ and $x=0.1$ in the range of $450-458 \mathrm{~cm}^{-1}$ could be assigned to $\mathrm{Li}^{+}-\mathrm{O}^{2-}$ complexes at the octahedral site. The intensity of this band goes on decreasing with increasing $x$ since the $\mathrm{Li}^{+}$content decreases with increasing $x$, so it persists only up to $x=0.1$. It completely disappeared for $x \geq 0.3$.

The threshold frequency $v_{\text {th }}$ for the electronic transition can be determined from the maximum point of the absorption spectra [20]. These threshold values are illustrated in Figure 4. It is found that the threshold frequency $\left(v_{\text {th }}\right)$ decreases with increasing Mn content for $x \geq 0.1$, that is, with decreasing both $\mathrm{Fe}^{3+}$ and $\mathrm{Li}^{+}$concentrations.

The force constant can be calculated for tetrahedral site $\left(k_{t}\right)$ and octahedral site $\left(k_{o}\right)$ by using the method suggested by Waldron [20]:

$$
\begin{gathered}
K_{t}=7.62 \times M_{A} \times v_{1}^{2} \times 10^{-7} \mathrm{~N} / \mathrm{m}, \\
K_{o}=10.62 \times \frac{M_{B}}{2} \times v_{2}^{2} \times 10^{-7} \mathrm{~N} / \mathrm{m},
\end{gathered}
$$


TABLE 2: Cation distribution of the Li-Mn ferrite samples (with $0.0 \leq x \leq 1.0$ ).

\begin{tabular}{lc}
\hline$x$ & Cation distribution \\
\hline 0.0 & $\left(\mathrm{Fe}^{3+}\right)^{\mathrm{A}}\left[\mathrm{Li}_{0.5}^{+} \mathrm{Fe}_{1.5}^{3+}\right]^{\mathrm{B}} \mathrm{O}_{4}^{2-}$ \\
$0.1 \leq x \leq 0.5$ & $\left(\mathrm{Fe}_{1-x}^{3+} \mathrm{Mn}_{x}^{2+}\right)\left[\mathrm{Li}_{0.5-0.5 x}^{+} \mathrm{Fe}_{1.5+0.5 x}^{3+}\right] \mathrm{O}_{4}^{2-}$ \\
$0.5<x \leq 1.0$ & $\left(\mathrm{Fe}_{1-x+y}^{3+} \mathrm{Mn}_{x-y}^{2+}\right)\left[\mathrm{Li}_{0.5-0.5 x}^{+} \mathrm{Mn}_{y} \mathrm{Fe}_{1.5+0.5 x-y}^{3+}\right] \mathrm{O}_{4}^{2-}$ \\
\hline
\end{tabular}

()$^{\mathrm{A}}$ : A-site and []$^{\mathrm{B}}$ : B-site.

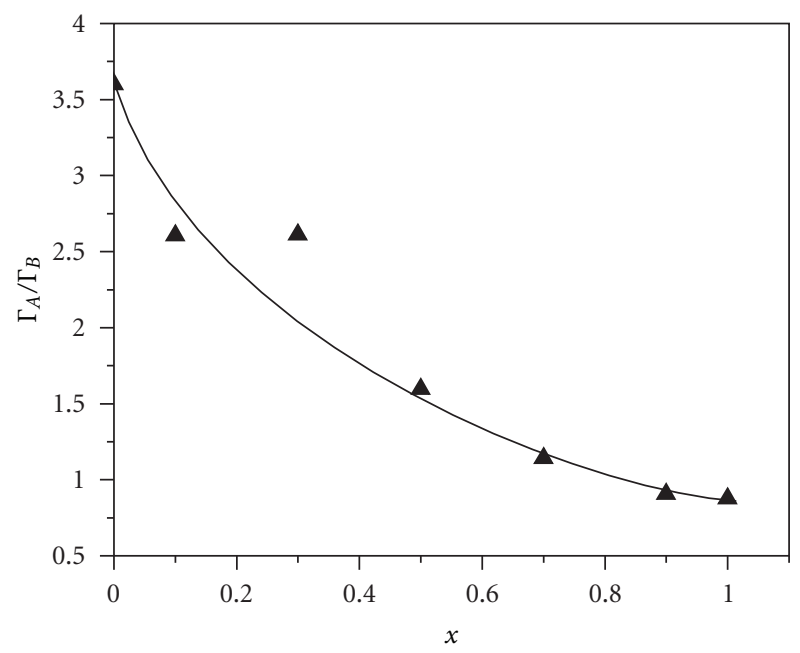

Figure 5: Change in half band width ratio $\left(\Gamma_{A} / \Gamma_{B}\right)$ against composition $x$.

where $M_{A}$ and $M_{B}$ are the molecular weights of cations at Aand B-sites, respectively. Both $M_{A}$ and $M_{B}$ were calculated from the cation distribution formula suggested in Table 2. The calculated values of the force constants $K_{t}$ and $K_{o}$ are listed in Table 3. It can be seen that $K_{t}$ decreases while $K_{o}$ increases with increasing $\mathrm{Mn}$ content. Furthermore the calculated values of $K_{t}$ are greater than those of $K_{o}$. However, the values of the bond length of A-site $\left(R_{A}\right)$ are smaller than those of B-site $\left(R_{B}\right)$. This is due to the inverse proportionality between the bond length and the force constants [21].

Also, from IR spectra, the values of half bandwidth for each site are calculated and the ratio $\Gamma_{A} / \Gamma_{B}$ is presented in Figure 5 . It can be noticed that the ratio $\Gamma_{A} / \Gamma_{B}$ decreases with increasing Mn content. The half bandwidth depends on the statistical distribution of various cations over the two sites [16]. This dependence is related to the replacement process that occurs between the smaller $\mathrm{Fe}^{3+}(0.064 \mathrm{~nm})$ and $\mathrm{Li}^{+}$ $(0.073 \mathrm{~nm})$ with the larger $\mathrm{Mn}^{2+}(0.08 \mathrm{~nm})$.

The Debye temperature $\theta_{D}$ can be calculated using the following relation [20]:

$$
\theta_{D}=\frac{\hbar C v_{a v}}{k}
$$

where $v_{a v}=\left(v_{A}+v_{B}\right) / 2, v_{A}$ is the frequency of the primary band of A-site, $v_{B}$ is the frequency of the primary band of Bsite, $\hbar=h / 2 \pi, h$ is the Plank constant, $k$ is the Boltzmann's constant and $C=3 \times 10^{10} \mathrm{~cm} / \mathrm{s}, C$ is the velocity of light. The calculated values of the Debye temperature are listed in Table 3. It can be noticed that all values of the Debye temperature are varying between 660 and $690 \mathrm{~K}$. These values have a great importance to determine the conduction mechanism of these ferrites. It can be seen that $\theta_{D}$ decreases with increasing $\mathrm{Mn}$ concentration. This behaviour can be discussed on the basis of a specific heat theory. According to this theory, electrons absorbed part of the heat and $\theta_{D}$ may decrease with increasing Mn concentration; this suggests that the conduction for these samples is due to electrons (i.e., $n$ type) [22].

3.2. Elastic Properties. To study the elastic properties of the spinel and garnet ferrites, a new technique based on infrared spectroscopy was developed by Modi et al. [8]. The elastic moduli can be evaluated by using the following relations.

The bulk modulus $(B)$ of solids is defined as

$$
B=\frac{1}{3}\left[C_{11}+2 C_{12}\right]
$$

where $C_{11}$ and $C_{12}$ are the stiffness constants. But according to Waldron [20], for isotropic materials with cubic symmetry like spinel ferrites and garnets, $C_{11} \approx C_{12}$, therefore, $B=C_{11}$. Also, the force constant $(k)$ is related to the stiffness constant by $\left[k=a C_{11}\right]$ [23], where $k$ is the average force constant $\left(k=\left(k_{t}+k_{o}\right) / 2\right)$. Further, the values of the longitudinal elastic wave $\left(V_{l}\right)$ and the transverse elastic wave $\left(V_{t}\right)$ have been determined as follows $[24,25]$ :

$$
V_{l}=\left(\frac{C_{11}}{d x}\right)^{1 / 2}, \quad V_{t}=\frac{V_{l}}{\sqrt{3}} .
$$

The variation in longitudinal $\left(V_{l}\right)$ and transverse $\left(V_{t}\right)$ sound velocity as a function of Mn composition $x$ is depicted in Table 3. It can be seen that both $V_{l}$ and $V_{t}$ decrease upon substitution of $\mathrm{Mn}$. The values of $V_{l}$ and $V_{t}$ are used to calculate elastic moduli of the ferrite specimens by using the following formulae [26]:

$$
\begin{gathered}
\text { mean elastic wave velocity } V_{m}=\frac{1}{3}\left[\frac{2}{V_{l}^{3}}+\frac{1}{V_{t}^{3}}\right]^{-1 / 3}, \\
\text { rigidity modulus }(G)=d_{x} V_{t}^{2}, \\
\text { Poisson's ratio }(P)=3 B-\frac{2 G}{6 B}+2 G, \\
\text { Young's modulus }(E)=(1+P) 2 G .
\end{gathered}
$$

The calculated values of different elastic moduli for the ferrites are listed in Table 3. From this table, it can be seen that, $B, E$, and $G$ slightly decrease with increasing Mn-content $(x)$. According to Wooster [24], the behaviour of elastic moduli is attributed to the strengthening of the interatomic binding between various atoms of the spinel lattice with increasing $\mathrm{Mn}$ content. The interatomic binding between various atoms is weakened continuously and therefore elastic moduli decreases with manganese content $x$. Similar results were observed in Ni-Zn ferrite [27] and Co$\mathrm{Zn}$ ferrite [28], where the interatomic binding between the various atoms decreases with increasing $\mathrm{Zn}$ content $x$. 


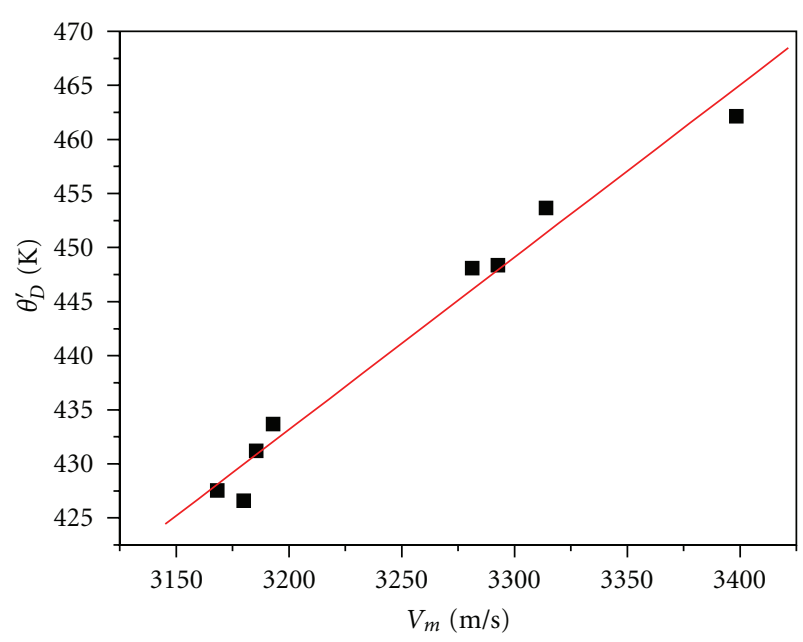

FIgURE 6: Debye temperature $\theta_{D}^{\prime}$ against average sound velocity $V_{m}$.

The Debye temperature $\theta_{D}^{\prime}$ was calculated by employing Anderson's formula [29]:

$$
\theta_{D}^{\prime}=\frac{h}{k_{B}}\left[\frac{3 N_{A}}{4 \pi V_{A}}\right]^{1 / 3} \cdot V_{m},
$$

where $V_{A}$ is mean atomic volume given by $(M / d x) / q, M$ is the molecular weight, $q$ is the number of atoms in the formula unit (equals 7), and $N_{A}$ is Avogadro's number. The calculated values are listed in Table 3. It is observed that the Debye temperature $\theta_{D}$ calculated according to Waldron equation (5) is higher than that calculated according to Anderson's formula $\theta_{D}^{\prime}(9)$, but both of them decrease with increasing manganese substitution.

A plot of average sound velocity $\left(V_{m}\right)$ against Debye temperature $\left(\theta_{D}^{\prime}\right)$ is shown in Figure 6. It is interesting to note from the figure that the average sound velocity increases linearly with the Debye temperature. A similar variation was also reported by Reddy [30] in $\mathrm{Mn}-\mathrm{Mg}$ mixed ferrites and by Ravinder [9] in Li-Mn mixed ferrites. This behaviour clearly indicates the direct relationship between the acoustic parameter (average sound velocity) and the important thermodynamic parameter (Debye temperature).

3.3. Dielectric Properties. AC conductivity $\tilde{\sigma}(\omega)$ with the dielectric properties (dielectric constant $\varepsilon^{\prime}$ and dielectric loss $\left.\varepsilon^{\prime \prime}\right)$ as a function of frequency $\left(f=10^{2}-10^{6} \mathrm{~Hz}\right)$ at room temperature for $\mathrm{Li}_{0.5-0.5 x} \mathrm{Mn}_{x} \mathrm{Fe}_{2.5-0.5 x} \mathrm{O}_{4}$ (where $x=0.0 \rightarrow$ $1.0)$ is shown in Figure 7. Ac conductivity increases slowly at lower frequencies, but after a certain frequency $\left(\approx 10^{4} \mathrm{~Hz}\right)$ it increases rapidly and reaches the highest value at $10^{6} \mathrm{~Hz}$. The dispersion in $\tilde{\sigma}$ with frequency has been explained by Koops theorem [31], which supposed that the ferrite compact acts as a multilayer capacitor. In this model, the ferrite grain and grain boundaries have different properties. The effect of the multilayer condenser rises with frequency; as a result, the conductivity increases. The conductivity is a complex quantity [32]:

$$
\widetilde{\sigma}=\sigma^{\prime}+i \sigma^{\prime \prime}
$$

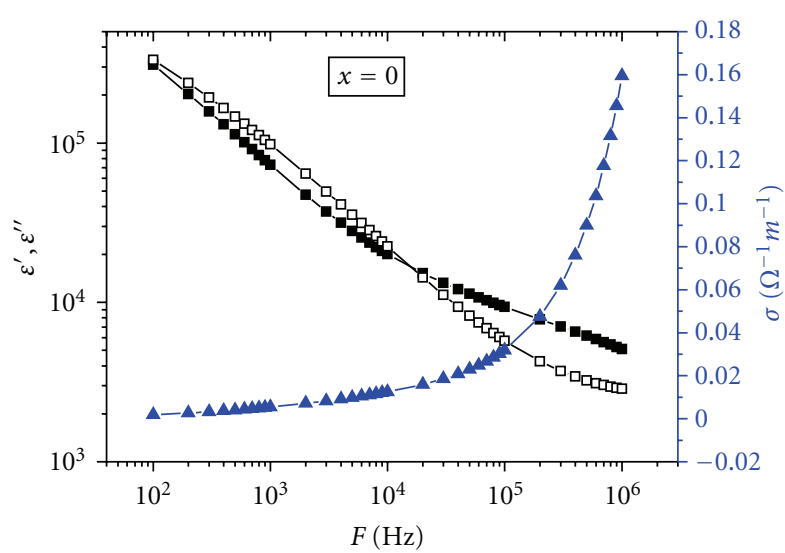

(a)

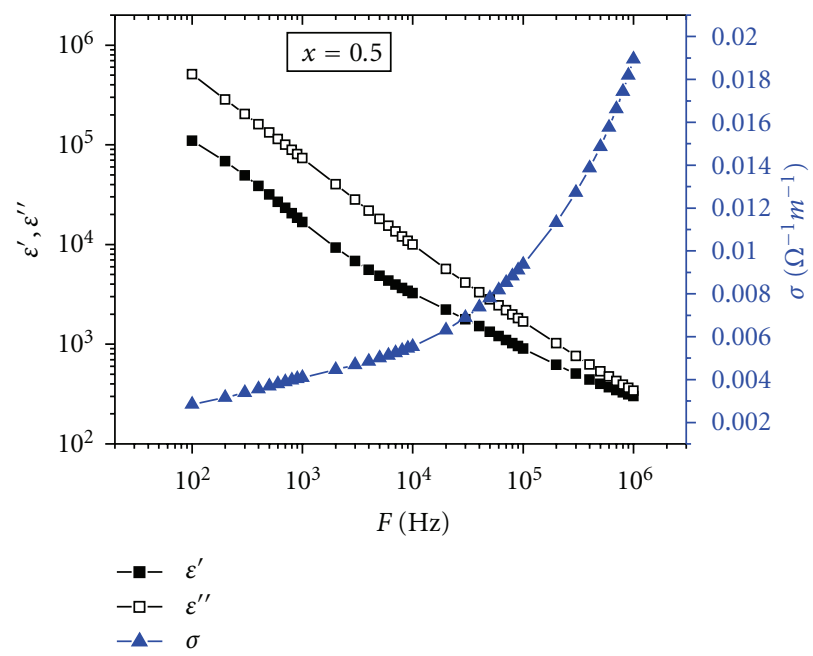

(b)

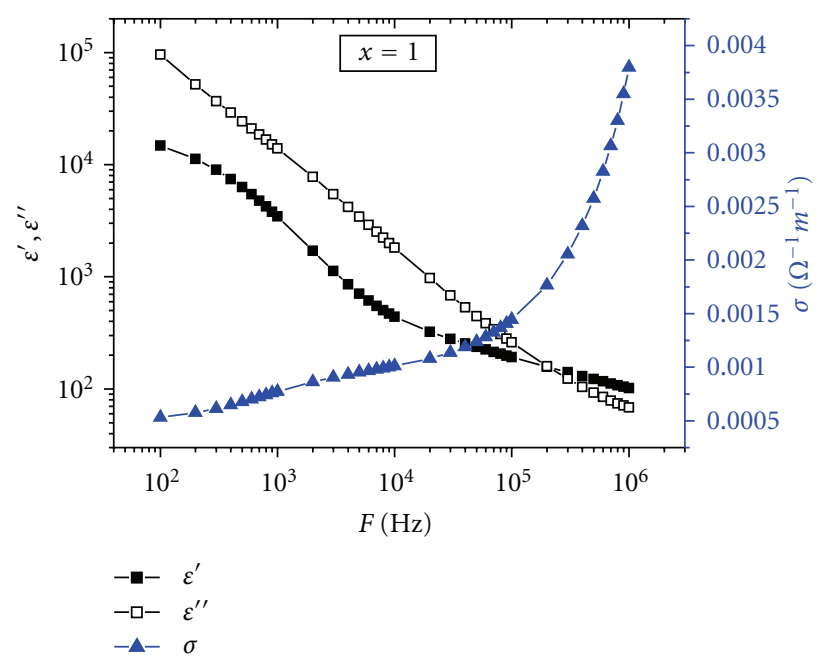

(c)

Figure 7: $\varepsilon^{\prime}, \varepsilon^{\prime \prime}$, and $\sigma$ versus frequency at room temperature for $x=0.0,0.5$, and 1 . 
TABLE 3: Force constants and elastic constants of the Li-Mn ferrite samples.

\begin{tabular}{|c|c|c|c|c|c|c|c|c|c|c|c|c|}
\hline$x$ & \multicolumn{2}{|c|}{$(\mathrm{N} / \mathrm{m})$} & \multicolumn{2}{|c|}{$(\mathrm{m} / \mathrm{s})$} & \multicolumn{3}{|c|}{$\mathrm{GPa}$} & $P$ & $\begin{array}{l}V_{m} \\
\mathrm{~m} / \mathrm{s}\end{array}$ & $\begin{array}{c}V_{A} \\
\left(10^{-6} \mathrm{~m}^{3}\right)\end{array}$ & $\begin{array}{c}\Theta_{D}^{\prime} \\
\mathrm{K} \\
\end{array}$ & \multirow{2}{*}{$\begin{array}{c}\Theta_{D} \\
\mathrm{~K} \\
693\end{array}$} \\
\hline 0.0 & 145.41 & 66.54 & 5171 & 2985 & 127.22 & 114.49 & 42.41 & 0.35 & 3314 & 6.22 & 454 & \\
\hline 0.1 & 142.03 & 66.97 & 5119 & 2956 & 125.22 & 112.7 & 41.74 & 0.35 & 3281 & 6.26 & 448 & 685 \\
\hline 0.3 & 144.35 & 69.62 & 5137 & 2965 & 127.82 & 115.04 & 42.61 & 0.35 & 3293 & 6.32 & 448 & 687 \\
\hline 0.5 & 130.78 & 74.01 & 4982 & 2876 & 121.89 & 109.71 & 40.63 & 0.35 & 3193 & 6.37 & 434 & 669 \\
\hline 0.7 & 128.83 & 78.04 & 4969 & 2869 & 122.69 & 110.43 & 40.89 & 0.35 & 3186 & 6.43 & 431 & 668 \\
\hline 0.9 & 125.44 & 82.06 & 4943 & 2853 & 122.78 & 110.51 & 40.93 & 0.35 & 3168 & 6.49 & 428 & 664 \\
\hline 1.0 & 124.87 & 83.85 & 4961 & 2864 & 122.78 & 110.49 & 40.93 & 0.35 & 3179 & 6.61 & 427 & 663 \\
\hline
\end{tabular}

The impedance of this model can be represented by the following equation:

$$
Z^{-1}=R^{-1}+j(2 \pi f c)
$$

where $f$ is the applied frequency and $R, C$ are the parallel equivalent resistance and capacitance of the material, respectively.

In general, the dielectric can be denoted by a complex dielectric constant $\varepsilon^{*}$, hence

$$
\varepsilon^{*}=\varepsilon^{\prime}-j \varepsilon^{\prime \prime},
$$

where $\varepsilon^{\prime}$ is the true permittivity, the "dielectric constant" (which describes the stored energy), while $\varepsilon^{\prime \prime}$ is the imaginary permittivity, the "dielectric loss" (which describes the dissipation energy).

The behaviour of both $\varepsilon^{\prime}$ and $\varepsilon^{\prime \prime}$ against frequency at room temperature is shown in Figure 7. The general trend for $\varepsilon^{\prime}$ and $\varepsilon^{\prime \prime}$ is decreasing with increasing frequency for all values of $x$. However, $\varepsilon^{\prime \prime}$ decreases faster than $\varepsilon^{\prime}$ over the same range of frequency. In the high-frequency range the value of $\varepsilon^{\prime}$ becomes closer to the value of $\varepsilon^{\prime \prime}$. This behaviour of a dielectric may be explained qualitatively by the supposition that the mechanism of the polarization process in ferrite is similar to that of the conduction process. Iwauchi [33] has pointed out that there is a strong correlation between the conduction mechanism and the dielectric behaviour of ferrites. The electrical conduction mechanism can be explained by the electron hopping model proposed by Heikes and Jonston [34]. The electron hopping $\left(\mathrm{Fe}^{2+} \leftrightarrow \mathrm{Fe}^{3+}\right.$ or $\mathrm{Mn}^{2+} \leftrightarrow \mathrm{Mn}^{3+}$ ) occurs by electron transfer between adjacent octahedral sites (B-sites) in the spinel lattice [35]. Thus by the electronic exchange:

$$
\mathrm{Fe}^{2+}+\mathrm{Mn}^{3+} \longleftrightarrow \mathrm{Fe}^{3+}+\mathrm{Mn}^{2+} .
$$

One can obtain local displacements of electrons in the direction of the applied electric field. These displacements determine the polarization of the ferrite. It is known that the effect of the polarization is to reduce the field inside the medium. Therefore, the dielectric constant of the substance may decrease substantially as the frequency is increased. Also, such a decrease can be attributed to the fact that the electric exchange between $\mathrm{Fe}^{2+}$ and $\mathrm{Fe}^{3+}$ ions cannot follow the external applied field beyond a certain frequency.
Figure 8 shows the variation of loss tangent $(\tan \delta)$ with frequency of the samples (where $\tan \delta=\varepsilon^{\prime \prime} / \varepsilon^{\prime}$ ). A maximum in $\tan \delta$ at a certain frequency $\left(f_{\mathrm{o}}\right)$ can be observed when $\varepsilon^{\prime}$ has a minimum value. The condition for observing a maximum $\tan \delta$ of a dielectric material is given by [36]

$$
\omega_{o} \tau=1 \text { turn, }
$$

where $\omega_{o}=2 \pi f_{\mathrm{o}}$ and $\tau$ is the relaxation time. This relaxation time is related to the jumping (hopping) probability per unit time, $p$, by the equation:

$$
\tau=\frac{1}{2 p} \quad \text { or } \quad f_{\mathrm{o}} \alpha p .
$$

This equation shows that $f_{o}$ is proportional to the hopping probability. It was found that $\tau=6.95 \times 10^{-4}, 7.47 \times 10^{-4}$ and $2.50 \times 10^{-4}$ s for $x=0.0,0.5$ and 1.0 , respectively.

3.4. Determination of Frequency Exponential Factor (s). Because hopping conduction mechanism was assumed for the Li-Mn ferrites, the ACconductivity $\tilde{\sigma}(\omega)$ can be represented by a power law [32]:

$$
\tilde{\sigma}(\omega) \alpha A \omega^{s},
$$

where $A$ is slightly dependent on temperature, $\omega$ is the applied frequency at which the conductivity $\tilde{\sigma}$ was measured, and the power $s$, which is a weak function of frequency, is determined to be 0.4-0.8 [32]. Pike [37] and Elliott [38] considered $s \leq 1$ and it is expressed by the following relation $[32,38]$ :

$$
s=1-\frac{4}{\ln \left(v_{\mathrm{ph}} / \omega\right)} .
$$

In the present study, the values of s were calculated from the relation of $\log \tilde{\sigma}$ versus $\log \omega$ as shown in Figure 9. This relation shows a straight line over $10^{4} \mathrm{~Hz}$ up to $1 \mathrm{MHz}$. The estimated values of the power $s$ were listed in Table 4 . It is found that the $s$-factor is composition dependent, where $s$ decreases up to $x=0.5$ by $55 \%$ and then increases by $35 \%$ with further increase in $x$.

Also, the phonon frequency $\nu_{\mathrm{ph}}$ for each Li-Mn ferrite was calculated at $f=5 \times 10^{5} \mathrm{~Hz}$ and compared with those calculated from IR spectra [4]. The values of the phonon frequency were tabulated in Table 4 . It was found that the 


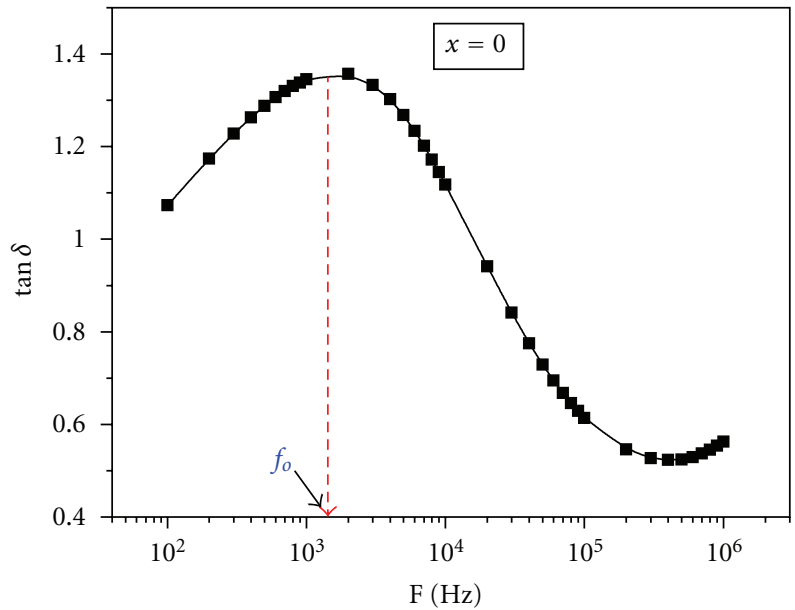

(a)

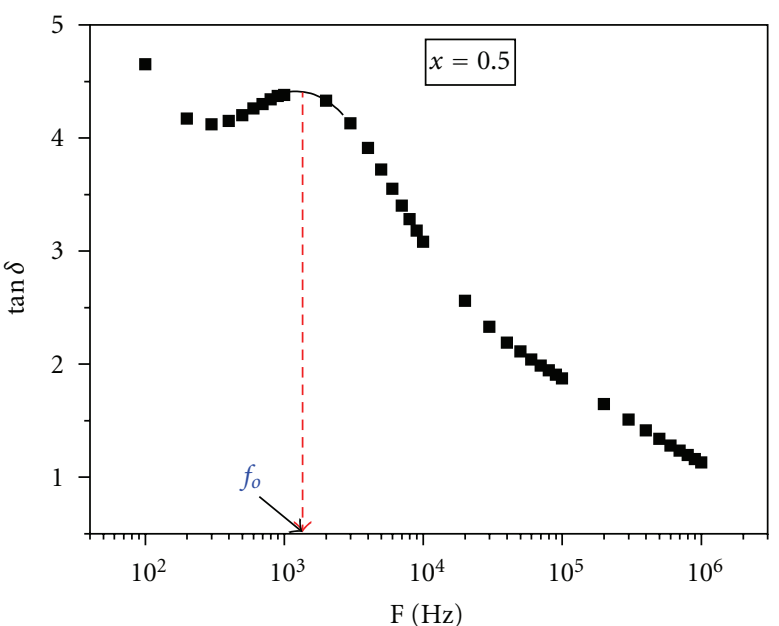

(b)

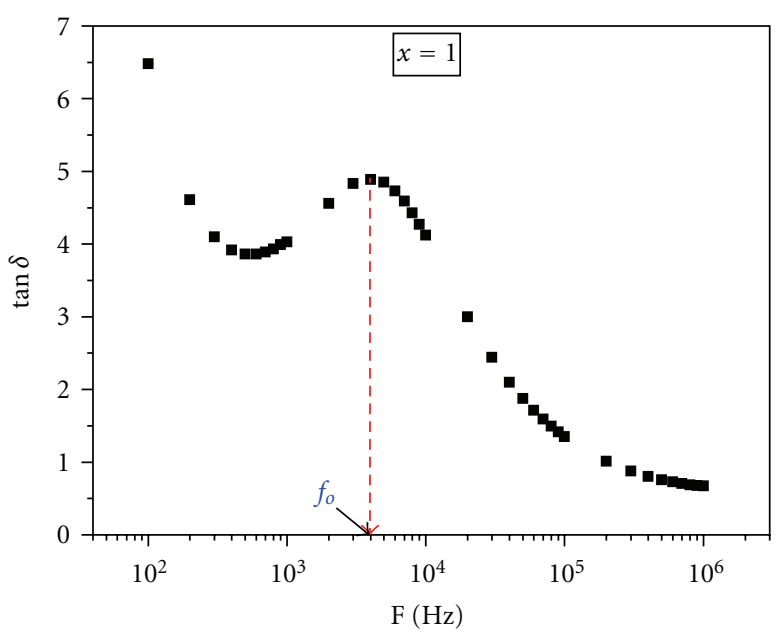

(c)

Figure 8: Variation in the dielectric loss tangent $(\tan \delta)$ with frequency at room temperature for $x=0.0,0.5$, and 1 .

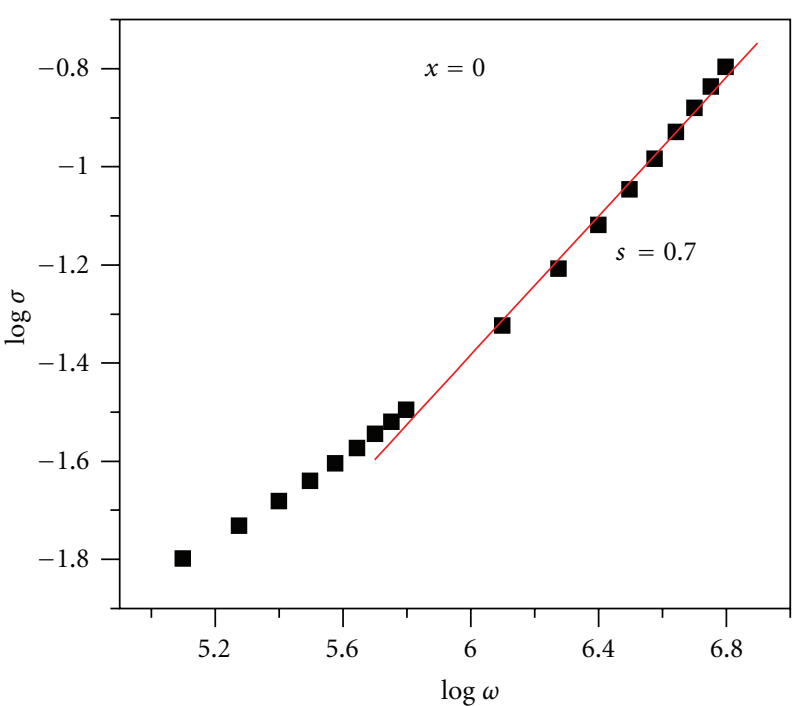

(a)

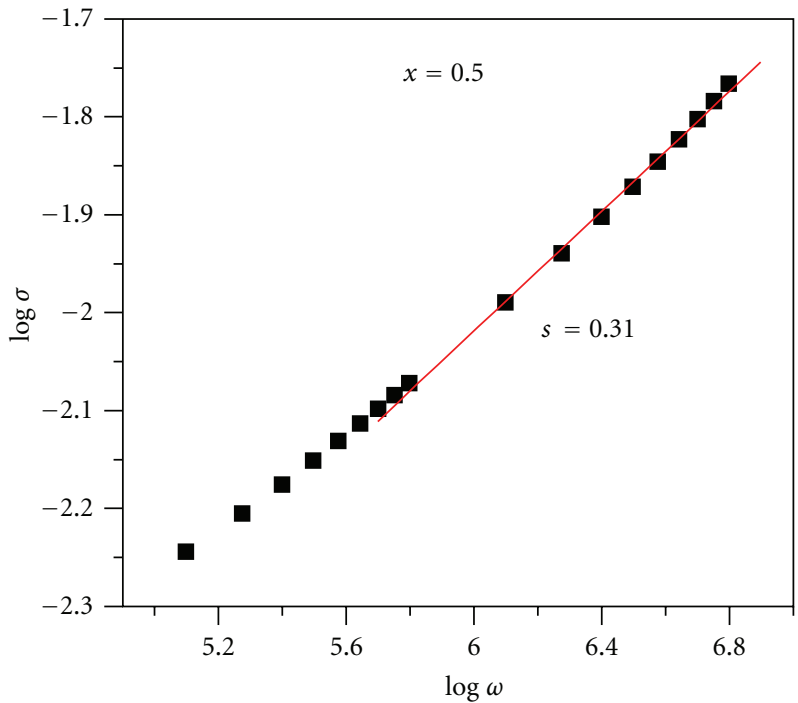

(b)

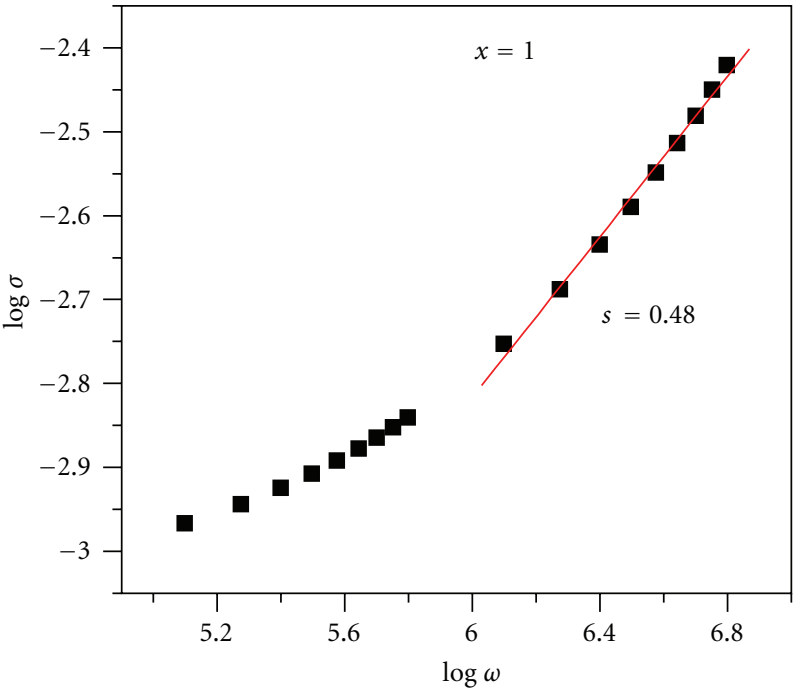

(c)

FIGURE 9: Variation in exponential factor $(s)$ with angular frequency $\omega$ at room temperature for $x=0.0,0.5$, and 1 . 
TABLE 4: Calculated $s$-values and $\nu_{\text {ph }}$ of the samples.

\begin{tabular}{ccccc}
\hline$x$ & $s$ & $\begin{array}{c}\nu_{\mathrm{ph}}(\mathrm{Hz}) \text { from } \\
(\log \omega-\log \sigma) \text { plots }\end{array}$ & $\begin{array}{c}\nu_{\mathrm{ph}}\left(10^{13} \mathrm{~Hz}\right) \text { from IR spectra } \\
\text { A-site }\end{array}$ & B-site \\
\hline 0.0 & 0.70 & $2.67 \times 10^{12}$ & 1.75 & 1.14 \\
0.1 & 0.64 & $6.21 \times 10^{11}$ & 1.73 & 1.13 \\
0.3 & 0.51 & $1.03 \times 10^{10}$ & 1.75 & 1.12 \\
0.5 & 0.31 & $1.00 \times 10^{9}$ & 1.67 & 1.12 \\
0.7 & 0.28 & $7.99 \times 10^{8}$ & 1.66 & 1.13 \\
0.9 & 0.38 & $2.09 \times 10^{9}$ & 1.64 & 1.13 \\
1.0 & 0.48 & $6.68 \times 10^{9}$ & 1.64 & 1.12 \\
\hline
\end{tabular}

values of $\nu_{\mathrm{ph}}$ calculated from the $(\log \tilde{\sigma}-\log \omega)$ plots are lower than those calculated from IR absorption spectra by a factor of about $10^{2}-10^{5} \mathrm{~Hz}$ (Table 4). This difference may be related to the nature of polarization in each case. At AC field, the polarization is due to ionic and electronic polarizations, while, in the IR spectra, the polarization is due to electronic polarization only. Also, the value of $v_{\text {ph }}$ at A-site is slightly higher than that of $v_{\mathrm{ph}}$ at $\mathrm{B}$-site. This may be attributed to the fact that at A-site is characterized by covalent bond only, while the B-site is characterized by both ionic and covalent bonds.

\section{Conclusions}

(1) IR spectra confirmed the formation of spinel structure and gave information about the distribution of ions between the two sites, tetrahedral (A-site) at $575 \mathrm{~cm}^{-1}$ and octahedral (B-site) at $370 \mathrm{~cm}^{-1}$.

(2) The behaviour of Debye temperature $\theta_{D}$ showed that electrons should make a significant contribution to the specific heat.

(3) The elastic bulk modulus $(B)$ and Young's modulus $(E)$ were dependent on Mn concentration.

(4) AC conductivity can be explained using the hopping model.

(5) The behaviour of dielectric constant and dielectric loss $\left(\varepsilon^{\prime}\right.$ and $\left.\varepsilon^{\prime \prime}\right)$ is due to the effect of polarization process on the reduction of the field inside the medium.

(6) The phonon frequency $v_{\text {ph }}$ calculated from IR spectra was higher than that calculated from AC conductivity by a factor of about $10^{2}-10^{5} \mathrm{~Hz}$, which was due to the different nature of polarization.

\section{References}

[1] P. P. Hankare, R. P. Patil, U. B. Sankpal et al., "Magnetic and dielectric properties of nanophase manganese-substituted lithium ferrite," Journal of Magnetism and Magnetic Materials, vol. 321, no. 19, pp. 3270-3273, 2009.

[2] E. Wolska, K. Stempin, and O. Krasnowska-Hobbs, "X-ray diffraction study on the distribution of lithium ions in $\mathrm{LiMn}_{2} \mathrm{O}_{4} / \mathrm{LiFe}_{5} \mathrm{O}_{8}$ spinel solid solutions," Solid State Ionics, vol. 101-103, part 1, pp. 527-531, 1997.
[3] A. Y. Lipare, P. N. Vasambekar, and A. S. Vaingankar, "X-ray, IR and dc electrical resistivity study of CaCI2-doped zinccopper ferrite system," Physica Status Solidi A, vol. 196, no. 2, pp. 372-378, 2003.

[4] S. A. Mazen, S. F. Mansour, E. Dhahri, H. M. Zaki, and T. A. Elmosalami, "The infrared absorption and dielectric properties of Li-Ga ferrite," Journal of Alloys and Compounds, vol. 470, no. 1-2, pp. 294-300, 2009.

[5] T. Nakamura, H. Demidzu, and Y. Yamada, "Synthesis and magnetic study on $\mathrm{Mg}^{2+}$-substituted Li-Mn spinel oxides," Journal of Physics and Chemistry of Solids, vol. 69, no. 10, pp. 2349-2355, 2008.

[6] P. P. Hankare, R. P. Patil, U. B. Sankpal et al., "Magnetic and dielectric properties of nanophase manganese-substituted lithium ferrite," Journal of Magnetism and Magnetic Materials, vol. 321, no. 19, pp. 3270-3273, 2009.

[7] A. M. Shaikh, S. A. Jadhav, S. C. Watawe, and B. K. Chougule, "Infrared spectral studies of Zn-substituted Li-Mg ferrites," Materials Letters, vol. 44, no. 3, pp. 192-196, 2000.

[8] K. B. Modi, U. N. Trivedi, M. P. Pandya, S. S. Bhatu, M. C. Chhantbar, and H. H. Joshi, "Study of elastic properties of magnesium and aluminum co-substituted lithium ferrite near microwave frequencies," in Microwaves and Optoelectronics, p. 223, Anamaya Publishers, New Delhi, India, 2004.

[9] D. Ravinder, L. Balachander, and Y. C. Venudhar, "Elastic behaviour of manganese substituted lithium ferrites," Materials Letters, vol. 49, no. 3-4, pp. 205-208, 2001.

[10] S. A. Mazen, "Infrared absorption and dielectric properties of Li-Cu ferrite," Materials Chemistry and Physics, vol. 62, no. 2, pp. 139-147, 2000.

[11] S. A. Mazen and A. M. El Taher, "The conduction mechanism of Cu-Si ferrite," Journal of Alloys and Compounds, vol. 498, no. 1, pp. 19-25, 2010.

[12] J. Smit and H. P. Wijn, Ferrites, John Wiley \& Sons, New York, NY, USA, 1959.

[13] V. G. Patil, S. E. Shirsath, S. D. More et al., "Effect of zinc substitution on structural and elastic properties of cobalt ferrite," Journal of Alloys and Compounds, vol. 488, no. 1, pp. 199-203, 2009.

[14] S. A. Mazen, M. H. Abdallah, R. I. Nakhla, F. Metawe, and H. M. Zaki, "X-ray analysis and IR absorption spectra of Li-Ge ferrite," Materials Chemistry and Physics, vol. 34, no. 1, pp. 3540, 1993.

[15] B. J. Evans and S. Hafner, "Mössbauer resonance of $\mathrm{Fe}^{57}$ in oxidic spinels containing $\mathrm{Cu}$ and Fe," Journal of Physics and Chemistry of Solids, vol. 29, no. 9, pp. 1573-1588, 1968.

[16] S. A. Mazen, F. Metawe, and S. F. Mansour, "IR absorption and dielectric properties of Li-Ti ferrite," Journal of Physics D, vol. 30, no. 12, pp. 1799-1808, 1997.

[17] O. S. Josyulu and J. Sobhanadri, "Far-infrared spectra of some mixed cobalt zinc and magnesium zinc ferrites," Physica Status Solidi A, vol. 65, no. 2, pp. 479-483, 1981.

[18] V. A. Potakova, N. D. Zverv, and V. P. Romanov, "On the cation distribution in $\mathrm{Ni1}-x-y \mathrm{Fe}_{x}^{2+} \mathrm{ZnyFe}_{2}^{3+} \mathrm{O} 4$ spinel ferrites," Physica Status Solidi A, vol. 12, no. 2, pp. 623-627, 1972.

[19] P. Tarte, "Infra-red spectrum and tetrahedral coordination of lithium in the spinel $\mathrm{LiCrGeO}_{4}$," Acta Crystallographica, vol. 16, p. 228, 1963.

[20] R. D. Waldron, "Infrared spectra of ferrites," Physical Review, vol. 99, no. 6, pp. 1727-1735, 1955.

[21] S. C. Watawe, B. D. Sutar, B. D. Sarwade, and B. K. Chougule, "Infrared studies of some mixed Li-Co ferrites," International Journal of Inorganic Materials, vol. 3, no. 7, pp. 819-823, 2001. 
[22] S. A. Mazen and A. M. Abdel-Daiem, "IR spectra and dielectric properties of $\mathrm{Cu}-\mathrm{Ge}$ ferrite," Materials Chemistry and Physics, vol. 130, no. 3, pp. 847-852, 2011.

[23] S. L. Kakani and C. A. Hemrajani, Text Book of Solid State Physics, Sultan Chand \& Sons, New Delhi, India, 3rd edition, 1997.

[24] W. A. Wooster, "Physical properties and atomic arrangements in crystals," Reports on Progress in Physics, vol. 16, p. 62, 1953.

[25] D. Ravinder and T. A. Manga, "Elastic behaviour of Ni-Cd ferrites," Materials Letters, vol. 41, no. 5, pp. 254-260, 1999.

[26] B. Raj, V. Rajendram, and P. Palanichamy, Science and Technology of Ultrasonics, Narosa Publishing House, New Delhi, India, 2004.

[27] S. Srinivas Rao and D. Ravinder, "Composition dependence of elastic moduli of gadolinium-substituted nickel-zinc ferrites," Materials Letters, vol. 57, no. 24-25, pp. 3802-3804, 2003.

[28] V. G. Patil, S. E. Shirsath, S. D. More, S. J. Shukla, and K. M. Jadhav, "Effect of zinc substitution on structural and elastic properties of cobalt ferrite," Journal of Alloys and Compounds, vol. 488, no. 1, pp. 199-203, 2009.

[29] O. L. Anderson, Physical Acoustics. Vol. III, Part B, Academic Press, New York, NY, USA, 1965.

[30] P. V. Reddy, "High-temperature elastic behaviour of Mn-Mg mixed ferrites," Physica Status Solidi A, vol. 108, no. 2, pp. 607611, 1988.

[31] C. G. Koops, "On the dispersion of resistivity and dielectric constant of some semiconductors at audiofrequencies," Physical Review, vol. 83, no. 1, pp. 121-124, 1951.

[32] N. F. Mott and E. A. Davis, Electronic Processes in NonCrystalline Materials, Clarendon Press, Oxford, UK, 1979.

[33] K. Iwauchi, "Dielectric properties of fine particles of $\mathrm{Fe}_{3} \mathrm{O}_{4}$ and some ferrites," Japanese Journal of Applied Physics, vol. 10, pp. 1520-1528, 1971.

[34] R. R. Heikes and W. D. Jonston, "Mechanism of conduction in Li-substituted transition metal oxides," Journal of Chemical Physics, vol. 26, no. 3, p. 582, 1957.

[35] G. H. Jonker, "Analysis of the semiconducting properties of cobalt ferrite," Journal of Physics and Chemistry of Solids, vol. 9, no. 2, pp. 165-175, 1959.

[36] M. B. Reddy and P. V. Reddy, "Low-frequency dielectric behaviour of mixed Li-Ti ferrites," Journal of Physics D, vol. 24, no. 6, pp. 975-981, 1991.

[37] G. F. Pike, "ac conductivity of scandium oxide and a new hopping model for conductivity," Physical Review B, vol. 6, no. 4, pp. 1572-1580, 1972.

[38] S. R. Elliott, "A theory of a.c. conduction in chalcogenide glasses," Philosophical Magazine, vol. 36, no. 6, pp. 1291-1304, 1977. 

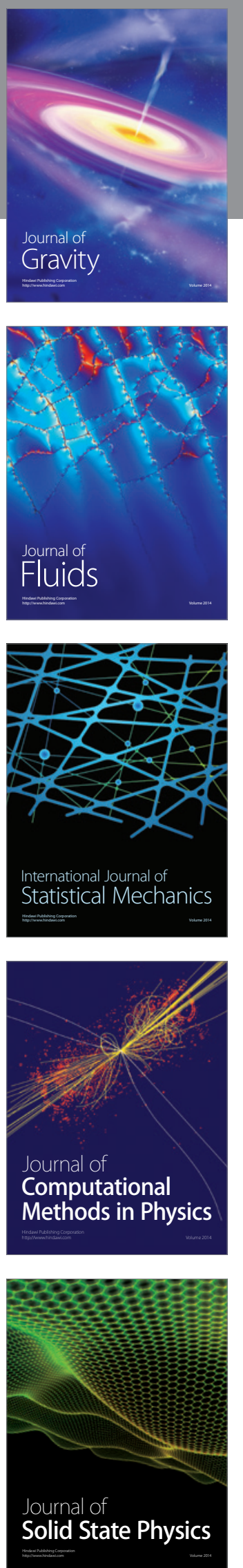
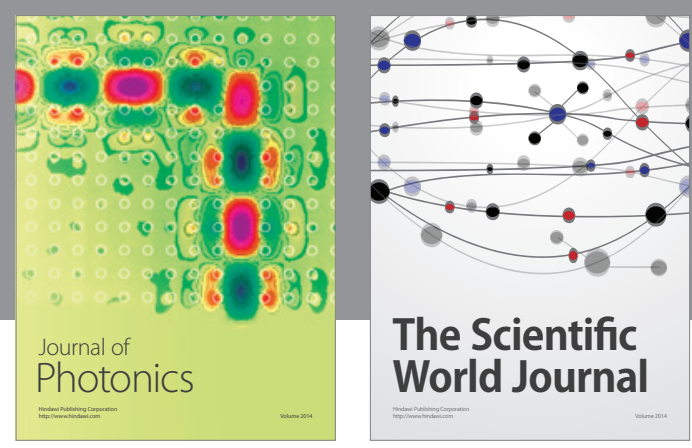

The Scientific World Journal

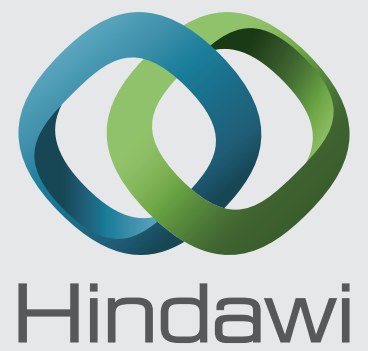

Submit your manuscripts at http://www.hindawi.com
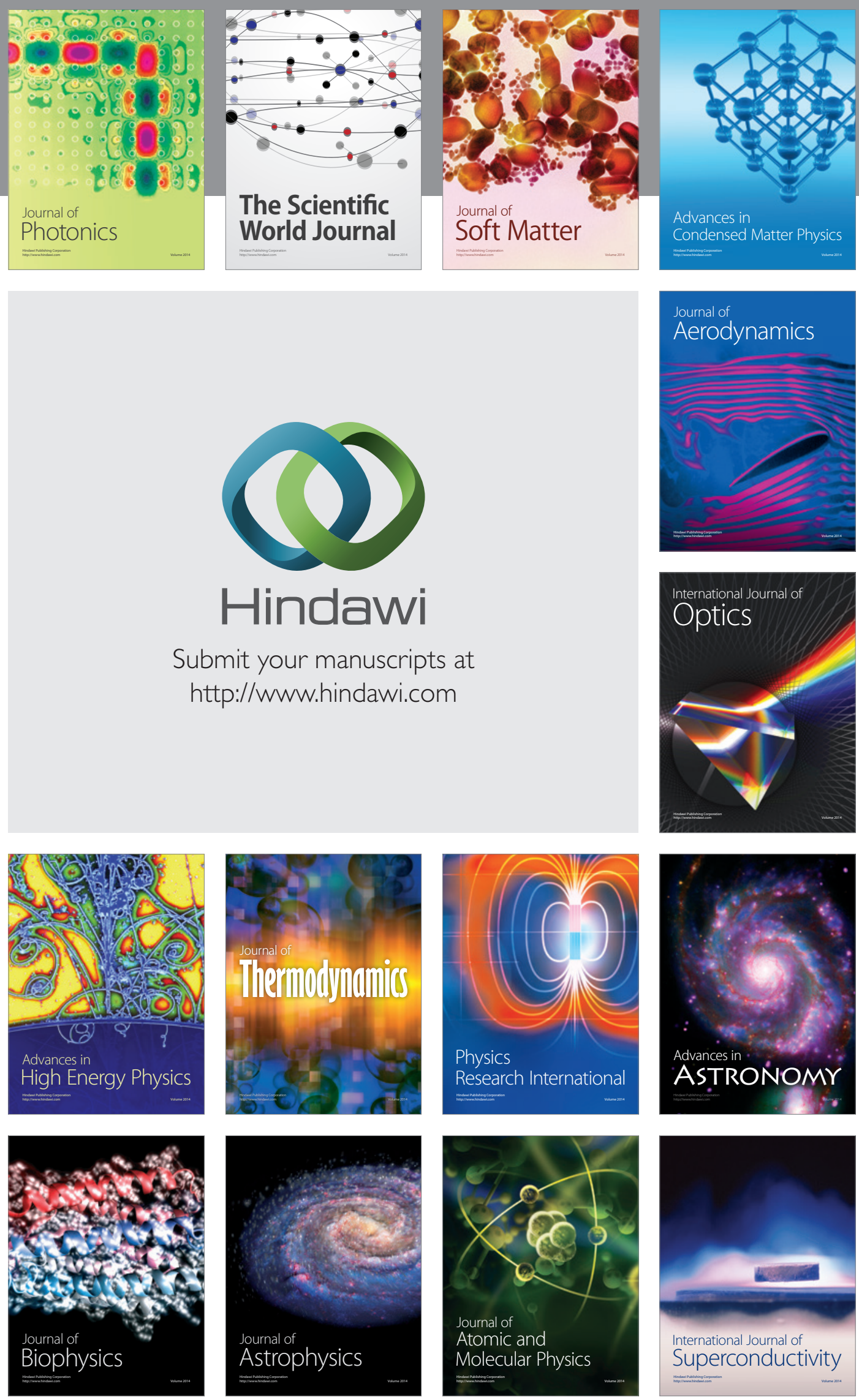
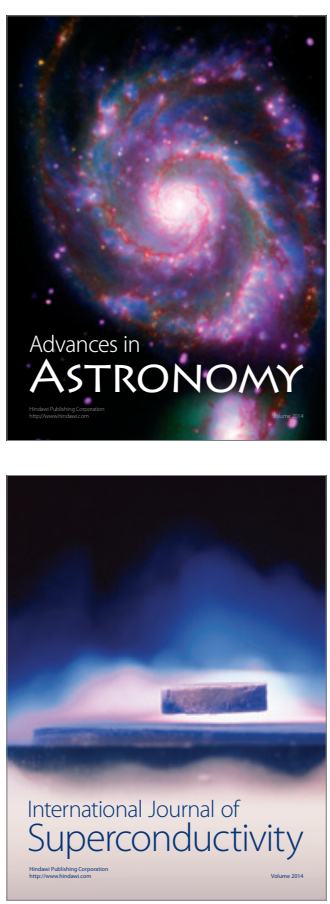